\title{
A VIOLÊNCA DE LOPE DE AGUIRRE NAS CRÔNICAS DO DESCOBRIMENTO E A SUA RELEITURA NO ROMANCE HISTÓRICO LATINO-AMERICANO - O EL DORADO
}

\author{
Alceni Elias Langner ${ }^{1}$ \\ Gilmei Francisco Fleck $^{2}$
}

RESUMO: Na era das navegações e colonizações espanholas na América, o mito indígena do El Dorado fomentou a corrida pelo ouro, para a qual muitas expedições foram organizadas, às cegas, pela floresta Amazônica adentro. Entre estas está a jornada governada por Pedro de Ursúa (1559-1561). Alguns dos eventos relacionados a esta expedição, e sua releitura pela ficção, são o foco desse trabalho, isso por emergir dela uma das personagens historiograficamente mais violentas e desconcertantes da colonização espanhola: Lope de Aguirre. Para tanto, usaremos como corpus de análise a crônica El Dorado, de Francisco Vázquez ([1562] 2007), e o romance histórico Una lanza por Lope de Aguirre, de Funes (1984). Em virtude das características específicas do romance, também serão realizadas discussões sobre a metaficção historiográfica, como uma das modalidades importantes desse gênero. Em quesitos teóricos, essa pesquisa utiliza como substrato autores como Hutcheon (1985) e Fleck (2017).

PALAVRAS-CHAVE: El Dorado; Lope de Aguirre; Romance Histórico; Metaficção Historiográfica.

ABSTRACT: During the time of the great navigations and the Spanish colonization in America, the indigenous myth of the El Dorado stimulated the gold rush, to which many expeditions were blindly organized through the Amazon forest. Among them, there is the journey led by Pedro de Ursúa (15591561). Some of the events related to this expedition and its rereading throughout fiction are the objective of this paper because one of the most violent and perplexing historiographic characters from the Spanish colonization, Lope de Aguirre, emerges from it. For this purpose, we are going to use as analytical corpus the chronicle El Dorado, by Francisco Vázquez ([1562] 2007), and the historical novel Una lanza por Lope de Aguirre, by Funes (1984). Due to the specific characteristics of the novel, discussions about historiographic metafiction will be performed as one of the modalities of this genre as well. This research relies on Hutcheon (1985) and Fleck (2017) for theoretical background.

KEYWORDS: El Dorado; Lope de Aguirre; Historical Novel; Historiographic Metafiction.

\footnotetext{
1 Aluno do Programa de Pós-graduação em Letras, nível de Mestrado, da Unioeste (Campus Cascavel). Bolsista CAPES. E-mail: alcenilang@hotmail.com.

2 Professor Associado da UNIOESTE/Cascavel na Graduação e Pós-graduação em Letras nas áreas de Literatura e Cultura Hispânicas. E-mail: chicofleck@yahoo.com.br.
} 


\section{INTRODUÇÃO}

Na obra El Viejo Mundo y el Nuevo (1492-1550), Elliott (1970) discorre a respeito das relações existentes entre a América colonizada e a Europa colonizadora, relações estas que dizem respeito, principalmente, à transformação da do espaço americano pela interferência do colonizador espanhol. Nesse aspecto o autor se refere à força abrupta das expedições quanto à clerezia e à doutrinação hegemônica imposta pela igreja católica. Por outro lado, o autor menciona, também, a presença da América no Velho Mundo. Esse ponto de seu relato diz respeito à relevância que a posse da colônia demandou nos esforços logísticos dos espanhóis.

Desde 1492 el Nuevo Mundo ha estado siempre presente en la historia de Europa, aunque esta presencia se ha hecho notar de distinta forma en épocas diferentes. Por esta razón América y Europa no deben estar sujetas a un divorcio historiográfico, a pesar de que su interrelación es un tanto vaga antes de finales del siglo XVII. ${ }^{3}$ (ELLIOTT, 1970, p. 20).

Essa relação é vista como vaga, segundo o autor, pelo fato de não existir um interesse significativo por informações do Novo Mundo na Europa no início do século XVI, a não ser pela troca de cartas e relações que acontecia diretamente com a coroa por parte dos Vice -Reis que governavam os territórios coloniais, os quais eram letrados e tinham, entre suas atribuições, o dever de coletar informações e enviá-las à corte. Embora os povos autóctones que habitavam a região do Peru e do México, Incas e Astecas, terem sido encontrados pelas expedições colonizadoras de Pizarro e Cortés em meados do século XVI, somente nos anos finais do século XVII é que publicações de impacto sobre essa realidade passam a ocorrer, como é o caso dos Comentarios Reales ${ }^{4}$ (1609), do Inca Garcilaso de la Vega. Esse fato estreita informações entre os continentes e faz com que uma relação menos restrita aos círculos de poder se estabeleça

Nesse sentido, ao compreendermos o contexto que estabelece as relações entre a Espanha colonizadora e a América colonial nos séculos XV e XVII, reiteramos nosso objetivo de remontar, histórica e literariamente, a configuração do mito El Dorado, e a representação da violência, a qual circunda Lope de Aguirre, naquelas escritas que se referem à expedição governada por Pedro de Ursúa, entre os anos de 1559-1561 e suas releituras ficcionais. Isso se efetua por meio de uma abordagem crítica ao texto historiográfico, representado pela crônica de Francisco Vázquez ([1562] 2007) e, de forma comparativa, ao romance histórico do escritor argentino Jorge Ernesto Funes, Una lanza por Lope de Aguirre (1984).

De acordo com Chevalier e Gheerbrant ([1906] 2012, p. XIX), os mitos são como “[...]

3 Nossa tradução livre: Desde 1492 o Novo Mundo esteve sempre presente na história da Europa, ainda que esta presença se fez notar de diferente forma em épocas diferentes. Por essa razão América e Europa não devem estar sujeitas a um divórcio historiográfico, apesar de que sua inter-relação é um tanto vaga antes de finais do século XVII.

4 Trata-se da primeira e mais importante obra da literatura peruana do período colonial, primeiro por ter sido escrita por um mestiço - de herança indígena americana e espanhola - e segundo por tratar de um resgate dos costumes e tradições regionais, especificamente no período inca, com um compêndio de referências importantes. Teve grande valor histórico até o século XIX, quando passa a ser questionado por historiadores devido ao auto grau de literariedade empregado. 
composições de conjunto, epopeias, narrativas, gêneses, cosmogonias, teogonias, gigantomaquias, que já começam a deixar entrever um processo de racionalização. [...]". Dessa forma, podemos compreender o mito do El Dorado, em sua materialidade, como uma narrativa que foi racionalizada pelos espanhóis, não somente pela permissão que o contexto geográfico e suas características exóticas lhes assentiam, mas, também, pela necessidade que tinham de crer que um lugar como o que foi descrito a eles pelos autóctones realmente existia.

Na introdução à obra El Dorado: Crónica de la expedición de Pedro de Ursúa y Lope de Aguirre, de Vázquez ([1561]1987), o historiador responsável pela organização da publicação, Ortiz de la Tabla, escreve que: "En el mito de El Dorado confluyen realidades y fantasías, anhelos e intereses de diversos grupos humanos." (ORTIZ DE LA TABLA, 1987, p. 18). Esse excerto ganha substância quando o associamos ao fascínio que esse tesouro causava nos espanhóis do século XVI, pois, apesar de nunca visto, as descrições hiperbólicas que os índios brasiles narram aos espanhóis lhes atiça a imaginação e a cobiça daqueles que estavam em uma corrida pelo ouro não tem mais limites. (VÁZQUEZ, 1978, p. 47-48).

Na obra Historia General Moderna (1981, p. 236), de Vicens Vives, tal qual na obra de Ciro Bayo (1915) Los caballeros del Dorado, encontramos uma lista com a relação das expedições que precederam (ou sucederam) a jornada organizada por Ursúa em busca das riquezas do reino de Omágua e do príncipe Dorado (El Dorado). Entretanto, Vives (1981) também se refere à corrida desmedida pelas riquezas minerais, bem como pelas especiarias, espalhadas por todo o território conquistado, visto que, na Espanha, nesse período, o ouro ganhara o status de luxo.

Se de um lado tínhamos, nessa época, a alta sociedade espanhola - usufruindo das riquezas provenientes das colônias -, do outro lado estava toda a população trabalhadora - na qual figuravam os camponeses e outros espanhóis que haviam embarcado nas frotas rumo ao "Novo Mundo", organizadas pela Casa de Contratação. Conforme consta do prólogo à obra Lope de Aguirre: Crónicas (1559-1561), de Mampel González e Escandell Tur (1981), a parcela trabalhadora era "[...] gente proveniente de los estratos con menor poder social y económico: soldados, plebeyos, segundones, gente desarraigada de su tierra."6 (MAMPEL GONZALEZ; ESCANDELL TUR, 1981, p. II).

Conforme as autoras revelam, esses trabalhadores embarcavam com a esperança de encontrar riqueza no "Novo Mundo". Eram homens sem nome; uma massa populacional que abarcava todo o contingente rebelde da Espanha, dentre os quais se encontrava, seguramente, a personagem Lope de Aguirre, a qual ocupará o protagonismo desta análise.

Apesar da distância temporal entre a escrita do texto historiográfico sobre Lope de Aguirre por Vásquez (1562) e sua releitura pela arte literária de Funes (1984), por meio do gênero romance histórico, em suas diferentes modalidades, é possível reinventar a história de forma verossímil, utilizando recursos e ferramentas que o gênero adotou e desenvolveu

\footnotetext{
5 Nossa tradução livre: No mito do El Dorado confluem realidades e fantasias, anseios e interesses de diversos grupos humanos.

6 Nossa tradução livre: Ou seja, pessoas provenientes de estratos com menos poder social e econômico: soldados, plebeus, segundões, pessoas desarraigadas de sua terra.
} 
ao longo dos anos. Nesse processo, o romance se apropria do discurso historiográfico e o revitaliza, de modo a atribuir novos matizes ao que era imutável. Conforme Fleck (2007, p. 150), "o passado torna-se, assim, exótico, e as regras de ação mais claras e mais propícias a uma espécie de aventura pessoal, pois proporcionam um maior envolvimento do leitor com a matéria narrada”. Isso nos dá permissão para realizarmos as comparações que propomos nas linhas subsequentes.

\section{LOPE DE AGUIRRE: ENTRE A FÚRIA DA HISTORIOGRAFIA E A AMENIDADE DA METAFICÇÃO HISTORIOGRÁFICA}

Ao buscarmos listar algumas das crônicas e relações - publicadas até o século XXI que tratam, especificamente, da jornada de Omágua e Dorado, encontramos, nas obras de Mampel González e Escandell Tur (1981), Esteves (1995), Jos (1927) e, mais recentemente, na de Martínez Tolentino (2010), um total de quinze crônicas diferentes. Contudo, selecionamos para nossa análise a crônica de Francisco Vázquez ([1962] 2007), por se tratar da referência utilizada por Funes em sua releitura desse passado, expressa no romance histórico Una lanza por Lope de Aguirre (1984), também corpus desta análise.

Sobre a publicação da crônica de Vázquez (1562), Esteves (1995) aponta a data de 1842 para a primeira publicação, em língua francesa, na coleção Nouvelles Annales des Voyages. Após, foi publicada em Madrid, em 1881, pelo marquês Fuensanta del Valle, na Colección de Bibliófilos Españoles, tomo XX, sendo reeditada por Serrano Sanz na Nueva Biblioteca de Autores Españoles, em 1909, tomo XV. Outra publicação, inclusive utilizada nessa análise, é organizada por Javier Ortiz de la Tabla, em 1987, a qual ganhou novas edições em 1989 e 2007.

Como base para algumas das crônicas, o texto de Francisco Vázquez ([1562] 2007), sem dúvida é o melhor texto narrativo e descritivo sobre a expedição, isso por possuir uma rica descrição espaço-temporal, uma linearidade histórico-narrativa convincente, além de dados historiográficos que se justapõem dentro de uma narrativa longa que se embebe na literariedade, conforme apontam os críticos Jos (1927) e Esteves (1995).

Quanto ao romance de Funes (1984), mencionado anteriormente, ao projetá-lo sob as propostas teóricas que embasam o gênero em questão, identifica-se com as características atribuídas à modalidade da metaficção historiográfica, conforme as definições de Hutcheon (1985, p. 92-93) e Fleck (2007, p. 161-162). A diegese apresenta apenas um fio narrativo que vai se configurando entre a composição estrutural do romance - o qual se apresenta divido em 29 capítulos que discutem o texto informado na crônica de Vázquez - e o diálogo estabelecido entre o autor - no caso o próprio Funes, que nessa instância entra na tessitura diegética para se tornar uma personagem - e Lope de Aguirre, como uma personagem na condição de um fantasma.

. Dessa narrativa altamente crítica e experimentalista, o autor lança mão de personagens com papel essencial para que sua pretensão seja alcançada. Essa pretensão se resume em discutir as verdades absolutas escritas pelo cronista Vázquez em 1962, das quais grande parte refere-se aos atos de violência cometidos por Lope de Aguirre na expedição. Dessa forma, o autor emprega no romance recursos como a paródia e a carnavalização a fim de 
construir a inversão daquele que foi tratado como tirano pela historiografia. Assim, o texto que se origina nas páginas do romance é definido pelas personagens como uma "crônica", tanto que a personagem espectral de Lope, em interlocução com o autor, o aborda como "cronista".

Nesse sentido, precisamos apontar os estudos mais recentes do professor Fleck (2017), os quais revelam três diferentes categorias para a modalidade romanesca da metaficção historiográfica: na primeira delas - os Novos Romances Históricos Metaficcionais - estão aqueles romances que apresentam características do novo romance histórico latino-americano articuladas ao recurso da metaficção, entretanto, apenas como uma ferramenta estrutural, não como uma "força motriz". Recurso esse utilizado em romances como Los Perros del Paraíso (1983), de Abel Posse (1983) e Chalaça (1985), de José Roberto Torero.

A segunda - Metaficções historiográficas - são aqueles romances em que a metaficção se torna guia da narrativa, embora recursos do novo romance histórico também se façam presentes. Fleck (2017) cita como exemplos os romances Vigília del Almirante (1992), de Augusto Roa Bastos, e Santa Evita (1995), de Tomás Eloy Martínez. A última categoria, na qual o romance de Funes (1984) atende às postulações, abarca as - Metaficções Historiográficas Plenas - romances que apresentam

[...] uma narrativa extremamente anacrônica, difusa e metaficcional, na qual a "história (re)contada" cede a maior parte do espaço à narrativa de "como essa história se narra e se narrou”. [...]. A todo momento, é explicitado ao narratário que a vos enunciadora tem conhecimento - e, mais importante, vale-se dele dos processos de criação estético-literários, compreendendo que a linguagem é um construto humano. [...] O diálogo do narrador com o narratário é constante e a autoconsciência da voz enunciadora é explicita e recorrente durante toda a narrativa. (FLECK, 2017, p. 94-95 - grifos do autor).

Essas prerrogativas da "metaficção historiográfica plena", defendidas pelos críticos, ficam ilustradas na forma como as duas personagens protagonistas, Lope de Aguirre e o autor - e nesse caso entenda-se como "autor" o próprio Funes que ultrapassa os limites entre ficção e realidade e insere-se dentro da tessitura narrativa como personagem - constroem o texto: cada referência e capítulo são discutidos previamente e estruturados pelas duas personagens. O autor - enquanto personagem narradora - atua como uma espécie de mediador, que comenta e insere novas referências e intertextos no decorrer do diálogo, como podemos observar no seguinte fragmento: "Usaremos para componer esta crónica tan original, la forma del diálogo, [...]. Para poner un poco de orden seguiremos a un solo cronista y hemos de elegir a Francisco Vázquez, [...]. Como historiador, nos quedaremos con Emiliano Jos."7 (FUNES, 1984, p. 25).

É dessa maneira que a voz enunciadora do discurso, a qual é fracionada entre os dois protagonistas, comparte com o narratário a estruturação e organização da escrita da obra, além das decisões que toma e as eleições que faz frente ao vasto material histórico que dis-

7 Nossa tradução livre: Usaremos para compor esta crônica tão original, a forma de diálogo, [...]. Para inserir um pouco de ordem, seguiremos somente um cronista, Francisco Vázquez, [...]. Como historiador, ficaremos com Emiliano Jos. 
põe. Dessa forma, ao considerarmos as condições existenciais da personagem Lope na obra - uma entidade espectral, atemporal e ainda responsável pela criação de um texto totalmente paródico que é discutido com o autor (personagem) da obra -, podemos classificá-lo na categoria das metaficções historiográficas.

Como o romance de Funes (1984) é composto por apenas um fio narrativo, extremamente metaficcional, é lícito, também, que se atribua a essa metaficção o adjetivo "plena", de acordo com os estudos dos autores mencionados. É desse único fio narrativo que brotam as indagações e os questionamentos da voz enunciadora do discurso quanto à veracidade presente no discurso do cronista Vázquez ([1562] 2007), cujas comparações nos damos a licença de ilustrar a continuação.

Nesse intento, é importante ressalvar o tratamento dado à personagem Lope de Aguirre na crônica do expedicionário, o qual tece uma descrição bem caricata, que se mescla entres dados físicos e psicológicos, mas que não poupa adjetivos para descrevê-la como um tirano violento e cruel, sem nenhuma capacidade para reconhecer ou praticar a bondade:

[...] hombre de hasta 50 años pequeño de cuerpo, $y$ de muy poco, mal agestado $y$ chupada la cara, los ojos, que si miraban de fijo le bullían [...] era de agudo y vivo ingenio para ser hombre sin letras. Fue natural de la ciudad de Oñate [...] era bullicioso y determinado, [...] gran sufridor de trabajos, especialmente del sueño [...], $y$ armador de toda maldad [...], nunca dijo bién de nadie [...], y finalmente todos los vicios del mundo juntos, y ninguna bondad tenia. ${ }^{8}$ (VÁZQUEZ, 2007, p. 169).

No fragmento, assim como ao longo de todo o texto, fica visível o empenho do autor em tornar violenta a imagem discursiva de Lope. Isso é perceptível quando utiliza termos como "armador de toda a maldade", associados a características que afetam os ideais cristãos, como se faz na menção a "todos os vícios do mundo". Contudo, essa descrição é questionada pela própria personagem Aguirre, no romance de Funes (1984): “'Tendría este Lope de Aguirre alguna favorable condición? ¿Qué causas pudieron animar a este sombrío hidalgo, y moverle a superar lo insuperable?" (FUNES, 1984, p. 20). Além disso, a missão da jornada também é questionada pela personagem Aguirre e comparada a uma viagem suicida, não só pela forma como foi organizada, mas por persistir após um histórico de fracassos. Nesse sentido, o Aguirre configurado por Funes questiona:

8 Nossa tradução livre: [...] homem de até 50 anos, pequeno de corpo, e muito pouco, de aparência ruim e cara chupada, os olhos que não olhavam fixamente [...] era de forte e esperto engenho para ser homem iletrado. Foi natural da cidade de Oñate [...] era agitado e determinado, [...] muito empenhado nos trabalhos, especialmente à noite [...], e arquiteto de toda maldade [...], nunca falou bem de ninguém [...], e finalmente todos os vícios do mundo juntos, e não tinha nenhuma bondade.

9 Nossa tradução livre: Teria este Lope de Aguirre alguma condição favorável? Que causas puderam animar este fidalgo sombrio, e mover-lhe a superar o insuperável? 
Cronista amigo: ¿Por qué se ordenó esta jornada que me tocó cumplir, sabiéndose todo lo que de ella se sabía, como acabas de escuchar? ¿Podía acaso esperarse de ella algún feliz suceso? ¿Y también con qué plan entonces, muchos de los que fuimos, llegamos a ella? ${ }^{10}$ (FUNES, 1984, p. 29).

Vázquez, o autor da crônica revisada pela ficção de Funes (1984), foi testemunha ocular dos fatos da expedição de Ursúa até a chegada à Ilha Margarita. Ali Vázquez se desvencilha do bando do caudilho, juntamente com Zúñiga, outro marañon cronista que configura entre os traidores de Aguirre na historiografia. De toda forma, a presença de Vázquez em grande parte dos eventos contribui para que o cronista adquira um certo prestígio ante o discurso historiográfico. Contudo, para a personagem Aguirre da obra de Funes, esse Vázquez era o verdadeiro arquiteto dessa tirania. Tal suposição da personagem se revela, logicamente, por meio do próprio discurso de Vázquez: "[...] Mira, cronista amigo, que a mano tiene siempre este Vázquez la guadaña de la muerte para ofrecerla, a fin de que se la use."11 (FUNES, 1984, p. 40).

No romance, a personagem Lope, em sua condição de ser espectral, é onipotente, pois ao mesmo tempo que esteve no passado, também está no presente, por isso detêm tanto referências oculares dos fatos ocorridos, quanto referências literárias e historiográficas posteriores. Por isso, é construído pelo autor com livre arbítrio nos julgamentos dos acontecimentos históricos, o que lhe permite criticar e duvidar das convenções apresentadas pela verdade absoluta hegemônica, característica bem demarcada da metaficção historiográfica plena, conforme Fleck (2017, p. 96). Nesse quesito, atentaremos para dois fatos registrados pela historiografia, especificamente na crônica de Vázquez ([1562]2007), que são retomados e questionados pela personagem Aguirre, fatos estes apontados no romance como os principais responsáveis por apagar a humanidade e tonalizar a violência em Lope. Primeiro, pela negação da religiosidade, condição que propicia sua demonização, e, depois, pela ampliação de seu caráter violento, reverberado pela hediondez no ato da morte de Elvira, sua filha.

No que se refere à religiosidade de Lope, a personagem da obra de Funes (1984) reitera alguns momentos em que a crônica de Vázquez se contradiz, pois, se Aguirre não acreditava realmente em Deus, com que intenção teria feito alguns atos, como, manter vivo o padre Contreras e confiar a ele uma carta importante, ou ainda, salvar os ídolos de uma igreja em chamas, momentos antes de sua morte? O interlocutor de Aguirre, o autor-personagem, concorda com esse apontamento e o defende utilizando, para isso, exemplos de termos utilizados por Aguirre na carta enviada ao Rei Felipe, filho de Carlos invencível, como "rogo a Deus" ou "Deus nos deu graça”. O interlocutor escreve que: “¿Adónde está entonces tu irreligiosidad, capitán, adónde tus blasfemias a dios y a los Santos?" (FUNES, 1984, p. 100).

Já na crônica, esse perfil é peremptório, visto que o cronista limita as possibilidades de uma ligação de Lope com o sagrado, colocando palavras de auto-condenação em sua boca:

10 Nossa tradução livre: Cronista amigo: Por que se ordenou esta jornada que me tocou cumprir, sabendo-se tudo o que já sabia-se dela, como acabas de ouvir? Podia acaso esperar-se dela algum sucesso? E também com que plano então, muitos dos que fomos, chegamos a ela?

11 Nossa tradução livre: [...] Olha, cronista amigo, que tem sempre à mão, este Vázquez a gadanha da morte para oferecer, para que se use. 
Decía este tirano maldito algunas veces que ya sabía de cierto que su alma no se podía salvar, y que estando vivo ardía en los infiernos, y pues no podía ser más negro el cuervo que sus alas que había de hacer cuantas crueldades y maldades pudiese, por donde sonase en nombre de Aguirre. Otras veces decía que Dios tenía el cielo para quien bien le sirviese, y la tierra para quien más pudiese [...]. Decía más, que no dejasen los hombres de hacer todo lo que su apetito les pudiese por miedo del infierno, que para ir al cielo sólo bastaba creer en Dios, y que no quería él soldados muy rezadores, sino que si fuese menester jugasen con el dominio el alma a los dados, y otras muchas herejías. ${ }^{12}$ (VÁZQUEZ, 2007, p. 168).

Com base nas leituras das crônicas e de romances históricos, como por exemplo Lope de Aguirre: Príncipe de la Libertad (1979), de Otero Silva, percebemos que seria pelo menos um equívoco trabalhar com a personagem Aguirre excluindo os rastros da sua religiosidade, contudo, a eliminação dessa faceta, conforme abordado no romance, corrobora para intensificar outra das máculas implantadas sobre sua imagem: a violência.

O ponto crucial para a elaboração desse perfil violento, sem dúvida, é forjado da espetacularização no ato da morte da filha de Lope, Elvira. Essa personagem desempenha um importante papel na jornada, pois é por meio dela que Lope tem sua casta exaltada, visto que D. Fernando de Guzmán, após assumir o governo da missão no lugar de Ursúa, promete casá-la com seu irmão, Martí de Guzmán, como uma mostra de consideração pela amizade de Aguirre: [...] la gran consideración que mi casta merecía a don Fernando, [...] cuando quiere casar a mi hija mestiza con su hermano don Martí, los dejo para tu intima reflexión. ${ }^{13}$ (FUNES, 1984, p. 50). Com base nesse escancarado apreço entre os dois soldados registrado nos textos históricos, a personagem espectral de Lope questiona e argumenta com seu interlocutor sobre o constante intento do cronista Vázquez ([1562] 2007) em empobrecer a sua imagem, delineando-o como um mero domador de potros, mal-apessoado e iletrado.

Ao se reportar à morte de Elvira, a crônica de Vázquez ([1562] 2007) relata esse momento como a mais pura manifestação do demônio: [...] revestido el demonio en él, hizo una crueldad mayor que todas las demás, que fue dar de puñaladas a una sola hija que traía, [...] dijo que lo hacía porque no se quedase en el campo y la llamasen hija del tirano [...]. ${ }^{14}$ (VÁZQUEZ, 2007, p. 166).

Contudo, no romance de Funes (1984), é o próprio autor-personagem, quem sai em defesa de Lope, alegando que, se Vázquez afirma em sua crônica que o caudilho nutria um amor imensurável pela filha, então tirar sua vida não deve ter sido algo muito simples de

12 Nossa tradução livre: Dizia este tirano maldito algumas vezes que já sabia de certo que não podia salvar sua alma, e que estando vivo ardia nos infernos, e que não podia serem mais negras as asas do corvo do que as suas, e que havia de fazer quantas crueldades e maldades pudesse, por onde fosse o nome de Aguirre. Outras vezes dizia que Deus tinha o céu para que bem lhe servisse. E a terra para quem mais pudesse [...]. Dizia mais, que os homens não deixassem de fazer tudo o que seu apetite lhes pedisse por medo do inferno, que para ir ao céu bastava somente crer em Deus, e que não queria ele soldados muito rezadores, se não que se fosse obrigação, jogassem com arbítrio a alma aos dados e outras tantas heresias. 13 Nossa tradução livre: [...] a grande consideração que minha casta merecia Don Fernando, [...] quando quer casar a minha filha mestiça com seu irmão Don Martí, os deixo para tua íntima reflexão.

14 Nossa tradução livre: [...] revestido o demônio nele, fez uma crueldade maior que todas as demais, que foi apunhalar sua única filha que trazia, [...] disse que o fazia para que não ficasse no campo e a chamassem filha do tirano [...]. 
se fazer. Na historiografia, Aguirre já sabia que, possivelmente, algo não ocorreria bem, devido as deserções frequentes e às más condições em que seus marañones se encontravam. Por isso, já vinha tentando encontrar uma forma de deixar sua filha "protegida" quando chegasse sua hora. Nos planos de Lope, a solução seria deixá-la com o marañon e cronista Pedrarias de Almesto, o qual nutria um sentimento amoroso por Elvira e tinha seu aval. Entretanto, quando Almesto deserta, as chances de sua filha ganhar "proteção" desaparecem.

No romance, o interlocutor de Aguirre defende a sua decisão em tirar a sua vida, porque realmente era a decisão mais acertada a se fazer naquele momento, não por vilania ou pela simples sede de matar, mas pelo livramento de algo mais duro que sua vida estaria sujeitada. Nesse sentido, é necessário que apontemos aqui a alteração do status quo de assassino, engendrado na historiografia, para a condição de sacrifício, conjuntura esta que ressignifica e restaura as características mais humanas da personagem.

El lleva consigo, entre su hueste, a una hija, que según el cronista "mostraba quererla más que a sî". Conoce él, este mundo de la soldadesca, donde su hija habría de quedar, después que él muriese. Ese hombre, de terrible e inaudito valor, siente que se estremece de espanto, con sólo pensar lo que ha de ser de ella cuando eso ocurra. Con la fuerza de su carácter, es de imaginar con que realismo terrible sin concesiones de milagros, se habrá pintado en su imaginación a ese dramático destino. ${ }^{15}$ (FUNES, 1984, p. 109).

Após encerrarem a discussão acerca dos equívocos relacionados à imagem discursiva de Aguirre, as duas personagens passam a discutir os apontamentos feitos pelo historiador espanhol Emiliano Jos (1927), uma das primeiras e mais importantes referências documentais sobre o tema. Primeiro discordam de Jos quando este condena as atitudes de Aguirre, por ter agido como um "justiceiro", fazendo valer a ordem com as próprias mãos, afirmando que o historiador

[...] olvidó que esas tantas y terribles sangrentas ocasiones, se dieron en la más remota selva de un mundo salvaje y desconocido, tanto que podía dudarse o no saberse, si algunas tierras por las que anduvieron caían dentro de la jurisdicción de rey de España o eran de la corona portuguesa. ${ }^{16}$ (FUNES, 1984, p. 126).

Ainda, outro questionamento é feito com relação à tripulação que acompanhava Aguirre. O historiador Jos aponta como exemplo de "bom desempenho e civilidade" a expedição de Orellana, anterior a de Ursúa, a qual não teve nenhum problema com conflitos

15 Nossa tradução livre: Ele leva consigo, entre sua tropa, uma filha, que segundo o cronista "demonstrava quere-la mais que a si”. Ele conhece este mundo soldadesco, onde sua filha ficaria, depois que ele morresse. Esse homem, de terrível e inaudito valor, sente que se estremece de espanto, só em pensar que o que pode ser dela quando isso vier a ocorrer. Com a força de seu caráter, é de imaginar com que realismo terrível sem concessão de milagres, se pintou em sua imaginação esse dramático destino.

16 Nossa tradução livre: [...] esqueceu que todas essas sangrentas e terríveis ocasiões, aconteceram na mais remota selva de um mundo selvagem e desconhecido, tanto que se podia duvidar ou desconhecer, se algumas terras por onde andaram caiam dentro da jurisdição do rei da Espanha ou se eram da coroa portuguesa. 
internos, a não ser os geográficos. Entretanto, para as personagens do romance de Funes (1984), essa condição é distinta entre as duas expedições, inclusive uma das mais evidentes, pois, diferentemente da tripulação que acompanhava Orellana, com Ursúa uniu-se um grupo de soldados rebeldes, já saturados de conflitos por domínios e posses de territórios e riquezas. O interlocutor da personagem espectral diz que: "[...] los que tu mandabas, eran los que habian entrado en las rebeliones y a quienes se llamaba alacranados sus cabezas, salieron de Perú emprendiendo esa jornada, de la que muchos de ellos podían sospechar hecha para que no volviesen." ${ }^{\prime 7}$ (FUNES, 1984, p. 127).

Ademais, o romancista busca um largo acervo de referências para que as duas personagens dissertem sobre o contexto e relação em que se encontrava a Espanha e a colônia, apresentando algumas personagens históricas que tiveram, segundo o romance, influência nas ações ou na história que se conhece hoje de Aguirre, como por exemplo Gonzalo Pizarro, pela trajetória semelhante à sua, e o Inca Garcilaso de la Vega, pela importância de sua obra Comentarios Reales (1606). Todavia, os protagonistas chegam a uma conclusão quando escrevem o último capítulo - "Imaginación y Conocimiento" - no qual retomam o historiador Jos. Na voz da personagem espectral de Aguirre, o que faltou para o estudioso foi um pouco de imaginação para associar a todo o conhecimento que acumulou:

Nuestro trabajo, amigo cronista, siguió con el comentario que entre nosotros hicimos sobre la falta de Imaginación del historiador que más investigó en mi vida; $y$ entre lo que tú y yo ahí dejamos dicho, tratamos de mostrar el mundo que él no supo ver. [...] Al siguiente capitulo lo titulamos "Imaginación y Conocimiento", y esas palabras dicen de lo que en él se trata. ${ }^{18}$ (FUNES, 1984, p. 232).

O romance se encerra com o desligamento entre a personagem humana, o autor, e a personagem espectral, Aguirre. Essa despedida é narrada repleta de sentimentos e afeto, enquanto o humano se mostra grato pela oportunidade de estar junto de uma entidade histórica tão importante. Já o fantasma reconhece o valor do seu amigo pelo papel de "justiceiro" que o seu trabalho cumpre, "[...] el que a mi juício has logrado con este trabajo [...]". (FUNES, 1984, p. 234). Esse papel de "releitura do passado" que o romance desempenha, de forma altamente crítica, muito corrobora com a desconstrução do perfil hegemônico da personagem abordada nesta análise, sobretudo por ter empregado em sua tessitura narrativa tantos recursos metaficcionais, o que nos ajuda a compreender melhor essa modalidade tão híbrida de romance.

17 Nossa tradução livre: [...] os que você comandava, eram os que haviam entrado nas rebeliões e a quem diziam ter problemas na cabeça, saíram do Peru começando essa jornada, da qual muitos deles suspeitavam que tivesse sido organizada para que não voltassem.

18 Nossa tradução livre: Nosso trabalho, amigo cronista, seguiu com o comentário que fizemos entre nós sobre a falta de imaginação do historiador que mais investigou minha vida; e entre o que tu e eu aqui deixamos dito, tratamos de mostrar o mundo que ele não soube ver. [...] Ao capítulo seguinte intitulamos "Imaginação e Conhecimento", e essas palavras dizem do que tratamos nele. 


\section{CONCLUSÃO}

Com base nas considerações feitas a respeito da crônica de Vázquez ([1562] 2007) sobre os acontecimentos envolvendo Lope de Aguirre na expedição de Ursúa (1559-1561) e do romance histórico de Funes (1984), que reelabora esse discurso hegemônico do passado, podemos perceber a forma distinta em que se apresenta a violência na configuração discursiva da personagem Lope de Aguirre. Essa configuração, amplamente crítica, contribui aos estudos sobre a importância do gênero romance histórico e suas possibilidades de revisitar o passado por meio de suas diferentes modalidades, pois permite ampliar o espaço imaginativo e questionador acerca de uma das personagens mais controversas do período da colonização Latino-americana.

Análises como a que propomos são formas de perceber os aspectos intra e extratextuais que afloram no romance histórico crítico latino-americano e as possibilidades que essa produção nos oferece como vias de descolonização para a América Latina. Nesse contexto, torna-se crucial e relevante entender o valor da produção literária, levada a cabo no período do boom da literatura latino-americana, quando foi escrita a maioria das obras desconstrucionistas do discurso histórico hegemônico sobre o nosso passado na literatura dos países antes colonizados. Tais produções, entre as quais está o romance de Funes (1984), possibilitaram novas perspectivas a respeito de fatos e personagens do passado que foram ressignificados pela ficção. Essas releituras têm relevância crucial, não apenas pela possibilidade da criação de um simulacro verossímil, o qual nos possibilita uma visão panorâmica da história, mas pela perspectiva ficcional de resgatar, das crônicas e relações históricas, os discursos que foram emudecidos e as vozes que foram suprimidas.

\section{REFERÊNCIAS:}

ALBUQUERQUE, A. B. de; FLECK, G. F. Canudos: Entre o multiperspectivismo de Vargas Llosa (1981) e a mediação de Aleilton Fonseca (2009). Curitiba: CVR, 2015.

BAYO, C. Los caballeros del Dorado. vol 1. Madrid: Clásica Española, 1915.

CHEVAliER, J. GHEERBRANT, A. Dicionário de símbolos. Trad. Vera da Costa e Silva. 26 ed. Rio de Janeiro: José Olímpio, 2012.

CORTÉS, H. Cartas de relación. Paris: Imprenta Central de los Ferro-carriles, 1866.

ELLIOTT, J. H. Viejo Mundo y el Nuevo (1492-1550). Trad. Rafael Sánches Matero. Madrid: Alianza Editorial, 1970.

ESTEVES, A. R. Lope de Aguirre: da história para a literatura. São Paulo: FFLCH-USP, 1995. Tese (Doutorado em Letras). 
FLECK, G. F. O Romance Histórico Contemporâneo de Mediação: Entre a Tradição e o

Desconstrucionismo - Releituras Críticas da História pela Ficção. Curitiba: CRV, 2017.

FLECK, G. F. A conquista do "entre-lugar": a trajetória do romance histórico na América. Gragoatá (UFF). v. 2. sem, p. 149-167, 2007.

FUNES, J. E. Una lanza por Lope de Aguirre. Buenos Aires: Platero,1984.

HUTCHEON, L. Uma teoría da paródia. Trad. Teresa Louro Pérez. 70 ed. Rio de Janeiro: Methuen \& Co, 1985.

JOS, E. La Expedición de Ursúa a El Dorado y la Rebelión de Lope de Aguirre. Huesca, Imprenta V. Campo, 1927.

MAMPEL GONZÁLEZ, E.; ESCANDELL TUR, N. Lope de Aguirre: crónicas 1559-1561. Barcelona: Universidad de Barcelona, 1981.

PUENTE Y OLEA, M. Los trabajos geográficos de la Casa de Contratación. Sevilla: Escuela Tipográfica e Librería Salesianas, 1900.

VÁZQUEZ, F.; ORTIZ DE LA TABLA, J. (introdução). El Dorado: crónica de la expedición de Pedro de Ursúa y Lope de Aguirre. Madrid: Alianza, 2007.

VICENS VIVES, J. História General Moderna. Barcelona: Ediciones Vicens Vives, 1981.

Recebido em 10 de agosto de 2017 Aceito em 20 de outubro de 2017 